\title{
Analysis of the influence of temperature variation on condensation crispness properties of metal materials
}

\author{
Meng baojin \\ Qinhuangdao Institude of Technology, Hebei Qinghuangdao 066100,China
}

Keywords: temperature variation; metal materials; condensation crispness measurement;

\begin{abstract}
The temperature variation have a larger effect on metal material condensation crispness properties, its impact is nonlinear, and the method for measuring the effect of temperature variation on metal material condensation crispness based on least square method is raised. The ultrasonic technology is utilized to collect related signal of metal material condensation crispness. The correlation between ultrasonic spectroscopy is calculated, and the relationship analysis model of the temperature changes and the metal material condensation crispness is given, to complete the measurement experiment for the effect of temperature change on the metal material condensation crispness. The experimental results show that, on the basis of the proposed algorithm to measure the effect of temperature variations on metal material condensation crispness, can greatly improve the accuracy of measurement, so as to meet the needs of practical applications.
\end{abstract}

\section{Introduction}

With the development of the construction industry, the construction safety requirements are also getting higher and higher [1]. Metal material as a main building materials, the condensation crispness is core factor influencing construction quality [2]. A large number of studies show that, temperature variation have great effect on metal material condensation crispness [3]. Therefore, in order to ensure the quality of construction, the effect of temperature variation on metal material condensation crispness have to be measured precisely [4]. Thus, measurement method of the effect of temperature variation on metal material condensation crispness, has become the core problem need to be researched in the construction field, and attracts the attention of many experts and scholars [5]. At current stage, the main measuring method of the effect of temperature variation on metal material condensation crispness includes the measurement method based on the feature spectrum algorithm, the measurement method based on image difference algorithm, the measurement method based on infrared signal [6-8]. The measurement method of effect of temperature variation on metal material condensation crispness plays a vital role on construction safety, therefore, has a broad space for developing [9].

With the traditional measurement method based on infrared signal to measure the effect of temperature variation on metal material condensation crispness, due to the uncertainty of temperature variation, the effect of temperature variation on metal material condensation crispness is non-linear, resulting in inaccurate traditional measuring method [10].

\section{The optimization of measurement method for the effect of temperature variation on metal material condensation crispness}

With the traditional measurement method to measure the effect of temperature variation on metal material condensation crispness, due to the uncertainty of temperature variation, the effect of temperature variation on metal material condensation crispness is non-linear, resulting in inaccurate traditional measuring method. To this end, a measurement method for the effect of temperature variation on metal material condensation crispness based on least square method is proposed.

The measuring method for metal material condensation crispness

During the measuring process of temperature variation on metal material condensation crispness, the covering area of the building is $\left(y_{k}, z_{k}\right)(k=1,2, \cdots, p)$, the corresponding feature space can be 
expressed by $\kappa=\operatorname{span}\left\{\eta_{1}, \eta_{2}, \cdots, \eta_{p}\right\}$, according to the following formula to calculate the square difference of metal material condensation crispness measurement error:

$$
\|\varepsilon\|_{2}^{2}=\sum_{k=0}^{p} \varepsilon_{k}^{2}=\sum_{k=0}^{p}\left[U^{*}\left(y_{k}\right)-z_{k}\right]^{2}=\min _{U(y) \in \eta} \sum_{k=1}^{p}\left[U\left(y_{k}\right)-z_{k}\right]^{2}
$$

There into: $U(y)=b_{1} \mu_{1}(y)+b_{2} \mu_{2}(y)+\cdots+b_{p} \mu_{p}(y)$ 。

A randomly selected sample point of metal material condensation crispness measurement is $\left(y_{k}, z_{k}\right)(k=1,2, \cdots, p)$, the coordinate of the point is described by $R_{0}\left(y_{0}, z_{0}\right)$. According to the following formula the distance between the sampling sites and the geometric center of building can be calculated:

$$
f=\sqrt{\left(y-y_{0}\right)^{2}+\left(z-z_{0}\right)^{2}}-t
$$

Because the calculation process is too complex, so, the above formula need to be simplified, thus obtains the following results:

$$
\bar{f}=\frac{1}{2 t}\left(\left(y-y_{0}\right)^{2}+\left(z-z_{0}\right)^{2}-t^{2}\right)
$$

Among them, $\quad(y, z) \in\left\{\left(y_{k}, z_{k}\right) \mid k=1,2, \cdots, p\right\}$, finally, it can be obtained the following results:

$$
\bar{f}=H(y)=c y^{T} y+d^{T} y+e
$$

Among them, $c=\frac{1}{2 t+1}, \quad y=\left(\begin{array}{l}y \\ z\end{array}\right), \quad d=\left(\begin{array}{l}d_{1} \\ d_{2}\end{array}\right)$, $e=\frac{y_{0}^{2}+z_{0}^{2}-t^{2}}{2 t}$ 。

With the following formula can measure the effect of temperature variation on metal material condensation crispness:

$$
\begin{aligned}
& d_{1}^{2}+d_{2}^{2}-4 c e=1 \\
& R_{0}=\left(y_{0}, z_{0}\right)=\left[-\frac{d_{1}}{2 c},-\frac{d_{2}}{2 c}\right] \\
& t=\sqrt{\frac{\|d\|^{2}}{4 c^{2}}-\frac{e}{c}}
\end{aligned}
$$

According to the method described above, the ultrasonic technology is utilized to collect related signal of metal material condensation crispness. The correlation between ultrasonic spectroscopy is calculated, according to the correlation to achieve anti interference treatment of ultrasonic, so as to provide data base for the measurement of the influence of temperature variation on the metal material condensation crispness. By using the least square method to complete the measurement of the influence of temperature variation on the metal material condensation crispness.

The relationship model of temperature variation and metal material condensation crispness

Figure 1 is the structure schematic diagram of the metal material, the general metal material is strong coupling layer $\mathrm{A}$, the condensation crispness of it is $E_{a}$, the thickness of the material is $t_{s}$. The bottom building structure is set to be $\mathrm{S}$, the thickness is $t_{s}$, the condensation brittleness is $E_{s}$. The above coefficients need to be analyzed for relationship analysis of temperature variation and metal material condensation crispness:

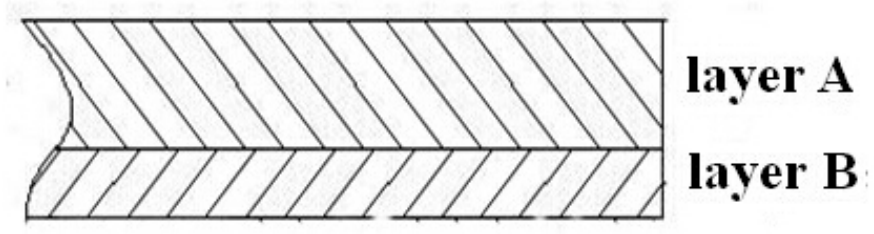

Figure 1 structure schematic diagram of two asymmetric layers

When measuring condensation brittleness, if temperature changes, condensation brittleness coefficient will change, thus affecting the mechanical properties of metal materials construction crispness. Condensation brittleness coefficient shows by metal material is:

$D_{0}=\frac{1}{3} E_{a}\left[\left(t_{a}+t_{s}-x\right)^{3}-\left(t_{s}-x\right)^{3}\right]$ 


$$
+\frac{1}{3} E_{s}\left[\left(t_{s}-x\right)^{3}+x^{3}\right]
$$

When the strain of metal material A layer changes with the temperature, metal material condensation crispness will have strain, temperature changes in the A layer is set to be X. Condensation crispness of metal materials changes to $x_{1}=\frac{E_{a}\left(t_{a}+X+t_{s}\right)^{2}+\left(E_{s}-E_{a}\right) t_{s}^{2}}{2 E_{a}\left(t_{a}+X+t_{s}\right)+2\left(E_{s}-E_{a}\right) t_{s}}$

Condensation brittleness coefficient becomes

$$
\begin{aligned}
D_{0}= & \frac{1}{3} E_{a}\left[\left(t_{a}+t_{s}-x\right)^{3}-\left(t_{s}-x\right)^{3}\right] \\
& +\frac{1}{3} E_{s}\left[\left(t_{s}-x\right)^{3}+x^{3}\right]
\end{aligned}
$$

Expression equation of the calculation of condensation brittleness before and after the change temperature are compared to know that, the reason to trigger metal material condensation crispness change is the coupling effect, produced when the temperature of A layer is changed, a condensed brittleness deformation $\mathrm{X}$ is formed in the process of metal material condensation crispness variation, which decides the metal material condensation crispness property. The coordinate equation of $\mathrm{A}$ layer temperature variation and metal material condensation brittleness $\mathrm{X}$ is established as follow

$$
\int_{t_{s}-x}^{t_{a}+t_{s}-x+X} a \kappa Z d Z=X
$$

Through the above formula, it can be seen that, the bigger the temperature change is, the bigger the material condensation crispness will be. And the different temperature change have indirect effect on the change of metal material condensation brittleness, the different temperature change have nonlinear influence trend on the A layer. Unified treatment is processed for detected material temperature change, as shown in figure 2. Figure 2 is the relationship diagram of influence of temperature variation on different metal material condensation brittleness. Different temperature change in the experiment of a same metal material, have different effect on detected material condensation crispness deformation. Figure 3 is the relationship analysis diagram of temperature variation and condensation crispness under the same metal material.

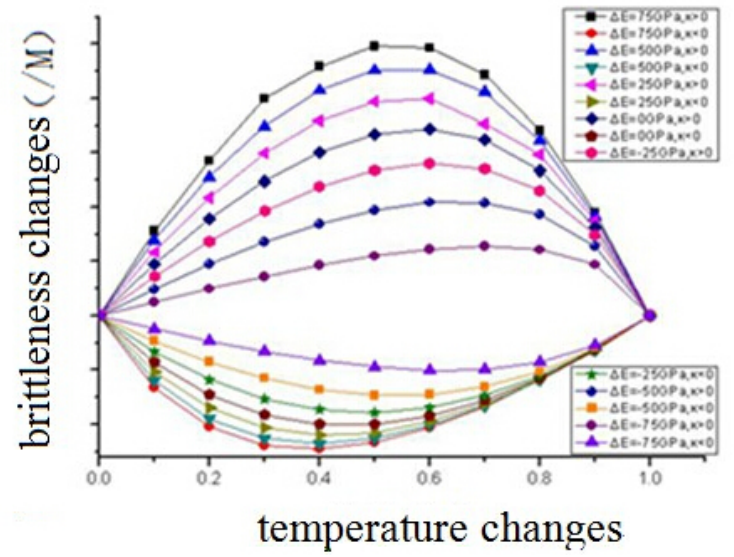

Fig. 2 Effect of temperature change of different materials on the brittleness variation 


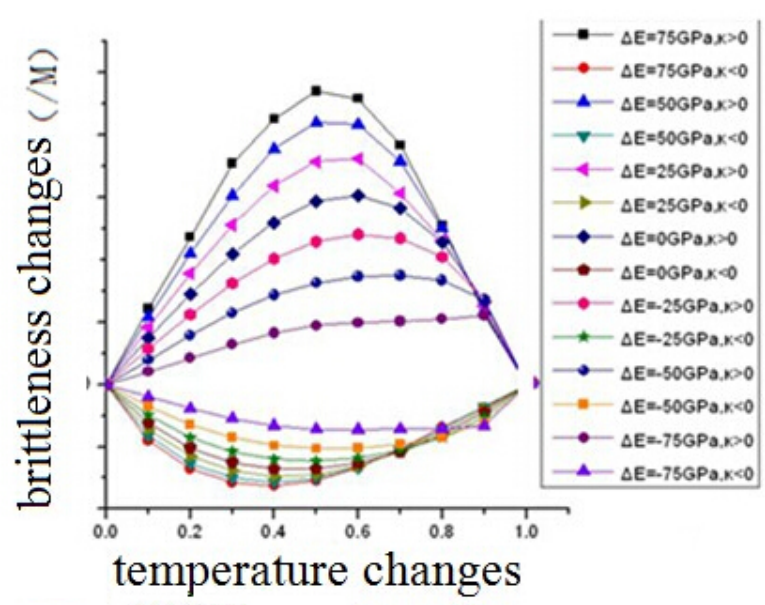

Figure 3 Effects of temperature changes of the same materials on condensation brittleness variation

\section{Comparative analysis of methods}

In order to validity the effectiveness of the measurement method proposed in the paper for the effect of temperature variation on metal materials condensation crispness, there is the need to perform an experiment. In the process of the experiment, the relevant data of sample can be described with the following table:

Table 1 experimental samples data tables

\begin{tabular}{|c|c|c|}
\hline Model & $\begin{array}{l}\text { Metal material area } \\
\left(\mathrm{m}^{2}\right)\end{array}$ & $\begin{array}{l}\text { The average } \\
\text { temperature } \\
\left({ }^{\circ}\right)\end{array}$ \\
\hline $\begin{array}{l}\text { Characteristic } \\
\text { spectrum model }\end{array}$ & 544 & 33 \\
\hline $\begin{array}{l}\text { Image interpolation } \\
\text { model }\end{array}$ & 646 & 37 \\
\hline $\begin{array}{l}\text { The infrared signal } \\
\text { method }\end{array}$ & 773 & 41 \\
\hline $\begin{array}{l}\text { The least square } \\
\text { method }\end{array}$ & 244 & 48 \\
\hline
\end{tabular}

In the area of average temperature value reaches -30 degree, respectively, with the traditional model and the proposed model to measure, the obtained experiment results can be described by Figure 4:

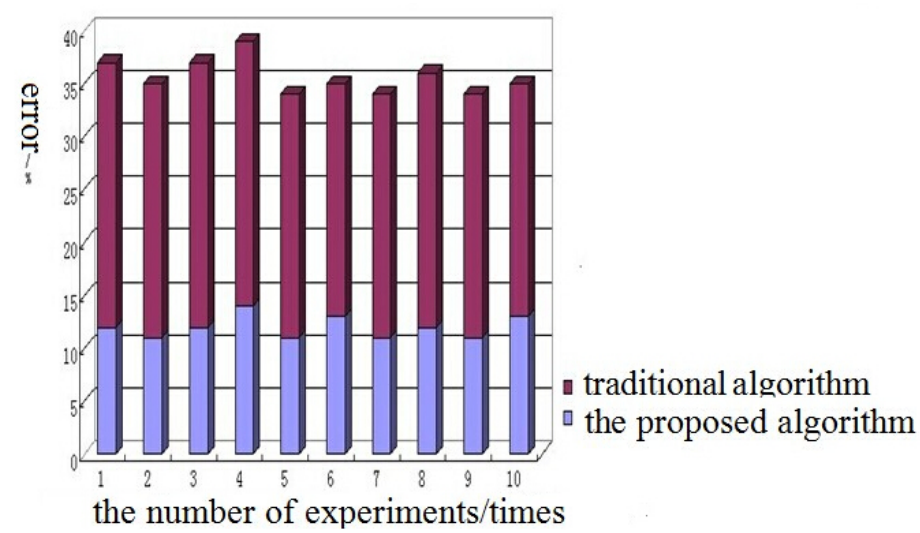

Figure 4 experimental results when areas temperature is $-30^{\circ}$

In the area of average temperature value reaches -40 degree, respectively, with the traditional model and the proposed model to measure, the obtained experiment results can be described by Figure 5: 


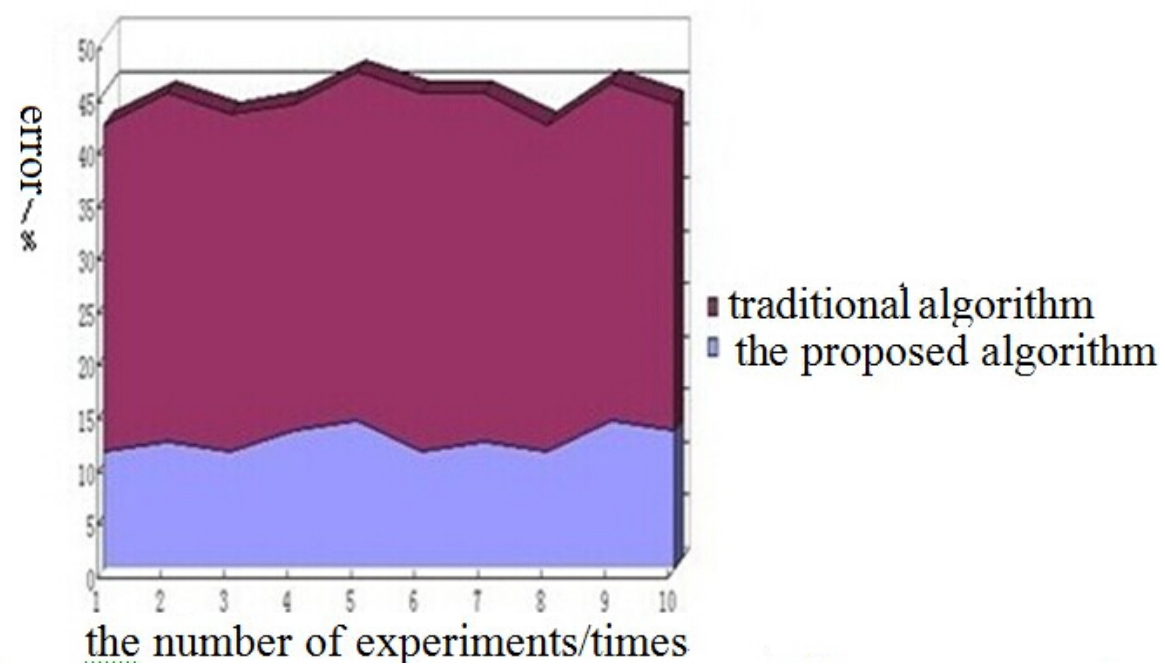

Figure 5 experimental results when areas temperature is $-40^{\circ}$

According to the two figures, it can be learned that the proposed model greatly improves the accuracy of measurement.

The relevant data in the experiment is analyzed and organized to get Table 2:

Table 2 measurement experiment data tables

\begin{tabular}{llll}
\hline & $\begin{array}{l}\text { the } \\
\text { number } \\
\text { of } \\
\text { model }\end{array}$ & $\begin{array}{l}\text { Actual } \\
\text { brittlenes } \\
\text { ments }\end{array}$ & $\begin{array}{l}\text { Measure } \\
\text { d } \\
\text { brittlenes } \\
\text { mentre }\end{array}$ \\
\hline $\begin{array}{l}\text { Characteristic spectrum } \\
\text { model }\end{array}$ & 44 & 0.23 & 0.38 \\
$\begin{array}{l}\text { Image interpolation model } \\
\text { The infrared signal method }\end{array}$ & 65 & 0.27 & 0.43 \\
The least square method & 57 & 0.31 & 0.49 \\
\hline
\end{tabular}

With the proposed model to measure the effect of temperature variation on metal materials condensation crispness, gets the results of the highest accuracy.

\section{Conclusions}

This paper presents the method for measuring the effect of temperature variation on metal material condensation crispness based on least square method. The ultrasonic technology is utilized to collect related signal of metal material condensation crispness. The correlation between ultrasonic spectroscopy is calculated, according to the correlation to achieve anti interference treatment of ultrasonic, so as to provide data base for the measurement of the influence of temperature variation on the metal material condensation crispness. By using the least square method to complete the measurement of the influence of temperature variation on the metal material condensation crispness. The experimental results show that, on the basis of the proposed algorithm to measure the effect of temperature variations on metal material condensation crispness, can greatly improve the accuracy of measurement, so as to meet the needs of actual construction process.

\section{References}

[1] Wang Fujun. Modeling and Simulation of the steady state operation of the ultrasonic motor [J]. Computer simulation, 2012.4: 405-408.

[2] M.Gonzalez-Audicana, J.L.Saleta, R.G.Catal, and R.Garcia.Fusion of multispectral and panchromatic images using improved IHS and PCA mergers based on wavelet 
decomposition[J]. IEEE Transactions on Geoscience and Remote Sensing. 2004, 1, 42(6). 1291 - 1299.

[3] Tham J Y, Shen L, Lee S L, Tan H H. A general approach for analysis and application of discrete multi-wavelet transforms [J]. IEEE Transactions on Signal Processing, 2000, 48(2) :457 464.

[4] Wang Haihun, Peng Jiaxiong. Research of image fusion based on Wavelet Transform [J]. Bulletin of science and technology, 2012,9(8):102 107.

[5] Zhang Jun, Yu Eryong, Wang Runsheng. The application of Balanced multiwavelet in the enhancement of image fusion [J]. Computer engineering and science, 2004,26(1):38 41

[6] Ruiyan Du, Jinkuan Wang, Fulai Liu. Qinping Zhou. An Effective Nulls Control Method [C]. Micro- wave Antenna, Propagation and EMC Technologies for wireless communications, 2009 3rd IEEE Inter- national symposium on, 2009(3):666-668.

[7] Zhang Chao, Wang Linxu, Li Sikun. Real-time simulation on the damage of explosion shock wave to bridge [J]. Computer and information technology, 2002.6.22-23

[8] Keyong Li,John Baillieul.Robust Quantization for digital finite Communication Bandw idth Control[J].IEEE Transaction on Automatic Control,2004,49(9):1573

[9] Zhao Zhilong, Liu Hui, Zhang Huan. Multiplicative noise removal using adaptive regularization term [J]. Electronic Science and technology, 2011, 24(1):1-3

[10] Yu Zufeng, Yang Yi, Gu Zhenxiong. Application of in mobile mapping system for road in the informatization construction [J] Shanxi building, 2012.5:226-227. 